\title{
Can results from limnocorral experiments be transferred to in situ conditions?
}

\section{(Biomanipulation in Limnocorrals VI)}

J. Bloesch, P. Bossard, H. Bührer, H. R. Bürgi \& U. Uehlinger

Institute of Aquatic Sciences (EAWAG), Swiss Federal Institute of Technology (ETH), Ueberlandstrasse 133, CH-8600 Dübendorf, Switzerland

Key words: limnocorrals, biomanipulation

\begin{abstract}
In 1982-1984 eight limnocorral (LC) experiments, each lasting for two weeks, were performed in mesotrophic Lake Lucerne, Switzerland, to study the effects of biomanipulation (removal of crustaceans by $95 \mu \mathrm{m}$ filter nets) on zooplankton - phytoplankton relationships and epilimnetic carbon and phosphorus fluxes. Seston concentrations and to a lesser extent primary production rates were reduced in control LCs through zooplankton grazing, and settling flux increased through fecal pellet production. But $\mathbf{C}$ and $\mathbf{P}$ regeneration were not significantly affected.

We found several indications that the LCs, despite of their large size $\left(\sim 70 \mathrm{~m}^{3}, 3 \mathrm{~m}\right.$ in diameter and $11 \mathrm{~m}$ long) were artificial systems when compared to the surrounding lake: The eddy diffusion was diminished by about one order of magnitude, nutrients depleted (but phosphorus was supplied to the LCs), the phyto- and zooplankton showed lower standing crops in the control LCs than in the lake, the phytoplankton showed a shift from nannoplankton to netplankton, the crustacean zooplankton was mostly limited in their vertical migration, and the POC and PP sedimentation rates were increased. Moreover, in our set of experiments we always found outliers, which may have been caused by the different in situ conditions at the beginning of the experiments, and further enhanced by the complexity of the enclosed system.

The problems of the LC-technique, such as replicability, scaling (size and time) and data extrapolation are discussed. The impact of crustacean zooplankton on particulate matter, i.e. seston reduction and sedimentation enhancement, can be extrapolated on a qualitative rather than on a quantitative basis for the Lake Lucerne ecosystem.
\end{abstract}

\section{Introduction}

Limnocorrals or plastic enclosures are a widely recognized method to carry out in situ experiments (CEPEX, 1977; MELIMEX, 1979; Giesy Jr., 1980; Grice \& Reeve, 1982). As any other method, this experimental technique has advantages and disadvantages which have been thoroughly debated (Harte et al., 1980; Gächter \& Urech, 1983; Uehlinger et al., 1984). This type of experiment is carried out mainly under complex, near-natural conditions to avoid the limitations of laboratory experiments. Whereas, e.g., continuous algal cultures may contain one or a few species under well defined light and nutrient conditions, limnocorrals are thought to have environmental conditions and to contain planktonic communities quite similar to those found in the lake. However, it has been shown that the development of phytoplankton populations in undisturbed enclosures was significantly different from their de- 
velopment in the lake (Lund, 1972). A possible explanation for this discrepancy is the elimination of horizontal advection by mechanical barriers. This consecutively changes the physical, chemical and biological properties inside the enclosures, such as turbulence, light, nutrient concentration, primary production, and both plankton biomass and species composition.

There is a fundamental difference in the methodology of laboratory and limnocorral experiments; however, as Gächter \& Urech (1983) point out, both types of experiments are needed to improve our knowledge of ecological systems: A limnocorral experiment is performed mainly to study ecological or community effects without regard of detailed mechanisms. On the other hand, the main purpose of a lab experiment is to control environmental conditions and to evaluate single fundamental processes to elucidate the mechanisms behind cause-effect relationships. Both methods, however, suffer from the difficulty of extrapolation to in situ conditions. The benefit of the limnocorral technique is at the same time its crux, because the system, while closer to nature, is very complex and therefore not easy to understand.

Modern concepts of limnology are basically focused on the understanding of whole ecosystems. For example, epilimnetic nutrient cycles and trophic interrelationships have been intensively studied (e.g. carbon cycle: Wetzel et al., 1972; Tilzer, 1984; Quay et al., 1986; phosphorus cycle: Rigler, 1973; Lean \& Charlton, 1976; Bloesch et al., 1977; Richey, 1979). However, the role of zooplankton is still debated (Cembella et al., 1984). Whereas significant literature on zooplankton grazing influencing phytoplankton standing crop exists (Haney \& Hall, 1975; Gliwicz, 1980; De Mott, 1982; Lampert et al., 1986; Angehrn, 1986), the impact of zooplankton to nutrient regeneration, primary production, and sedimentation is not yet fully understood. Therefore, we performed limnocorral (LC) experiments in mesotrophic Lake Lucerne, Switzerland, to study the effects of biomanipulation on zooplankton phytoplankton relationships, and epilimnetic carbon and phosphorus fluxes (Uehlinger et al., 1984; Uehlinger \& Bloesch, 1987a; Uehlinger \& Bloesch, 1987b; Bloesch \& Bürgi, 1988; Bossard \& Uehlinger,
1988; Bürgi, 1988). The large crustacean zooplankton were removed with $95 \mu \mathrm{m}$ plankton nets during the deployment of some LCs as described by Uehlinger et al. (1984), whereas the unfiltered (control) LCs were supposed to contain a similar plankton population as found in the lake. In addition, different regimes of phosphorus fertilization were applied to prevent nutrient depletion inside the LCs. During two weeks, the dynamics of both ecosystems (in the filtered and control LCs) were studied. We hypothesized that differences between the LCs would be caused primarily by the effects of biomanipulation, since this was very effective.

The goals of this paper (finishing the series of publications subtitled 'Biomanipulation in Limnocorrals') are to summarize the results obtained from the 8 limnocorral experiments performed in $1982-1984$, to compare these results with lake data and to discuss the problem of extrapolation, and to draw some conclusions on the application of limnocorrals in ecological experiments.

\section{Methods}

Limnocorrals (LCs), $3 \mathrm{~m}$ in diameter, $11 \mathrm{~m}$ long and with a closed bottom were exposed in Lake Lucerne (nearshore at Kastanienbaum) as described by Uehlinger et al. (1984). Since the epilimnion extends to 10-15 $\mathrm{m}$, there was no thermal stratification inside the LCs. The plankton communities were manipulated in some LCs by removing the larger plankton with $95 \mu \mathrm{m}$ plankton nets at the beginning of the experiments. This screening was very effective, as at least $85 \%$, but mostly $>95 \%$ of the total crustacean zooplankton were removed in the $95 \mu \mathrm{m}$ filtered LCs (Table 1). In contrast, the concentrations of particulate matter and phytoplankton usuaily were not significantly changed through $95 \mu \mathrm{m}$ filtration (Bloesch \& Bürgi, 1988). In three experiments however, when larger algae were abundant, the screening affected also the net phytoplankton biomass. Damage of plankton cells through this treatment cannot be excluded, but was minimized by slow filtration and large volume $\left(\sim 70 \mathrm{~m}^{3}\right)$ filtered. Parallel control LCs contained a plankton community similar to that found in the lake. 
Table 1. Effect of biomanipulation ( $95 \mu \mathrm{m}$ filtration of lake water) on zooplankton biomass at the 1 st day of the experiments.

\begin{tabular}{|c|c|c|c|c|}
\hline \multirow{2}{*}{$\begin{array}{l}\text { Experiment } \\
\text { No. }\end{array}$} & \multirow[t]{2}{*}{ Time period } & \multicolumn{3}{|c|}{ Ratio filtered LC/control LC } \\
\hline & & $\begin{array}{l}\text { herbivorous } \\
\text { zooplankton }\end{array}$ & $\begin{array}{l}\text { carnivorous } \\
\text { zooplankton }\end{array}$ & $\begin{array}{l}\text { total } \\
\text { zooplankton }\end{array}$ \\
\hline 1: $82 / 1 \mathrm{~A}^{*}$ & 25 March - 6 April, 1982 & 0.21 & $<0.01$ & 0.12 \\
\hline $2: 82 / 1 B^{*}$ & same & 0.28 & $<0.01$ & 0.15 \\
\hline 3: $82 / 2$ & 17-29 June, 1982 & 0.16 & 0 & 0.14 \\
\hline 4: $83 / 1$ & 17-29 March, 1983 & 0.03 & 0.05 & 0.04 \\
\hline $5: 83 / 2$ & 26 May - 7 June, 1983 & $<0.01$ & 0 & $<0.01$ \\
\hline $6: 83 / 3$ & 30 June - 12 July, 1983 & $<0.01$ & 0 & $<0.01$ \\
\hline $7: 84 / 1 A^{*}$ & 24 May - 5 June, 1984 & 0.06 & 0 & 0.06 \\
\hline $8: 84 / 1 B^{*}$ & same & 0.05 & 0 & 0.05 \\
\hline
\end{tabular}

*Experiments with different regimes of $\mathrm{P}$ fertilization, $\mathrm{B}$ indicating higher $\mathrm{PO}_{4}-\mathrm{P}$ input than $\mathrm{A}$ (details given in Bloesch \& Bürgi, 1988).

The 'Aufwuchs' growing at the plastic walls was controlled and did not interfere within the 2 weeks experiments, and each experiment was started with newly constructed LCs. During the experiments, phosphorus $\left(4.8-47.7 \mathrm{mg} \mathrm{PO}_{4}-\mathrm{P} \cdot \mathrm{m}^{-2}\right.$, usually daily) was added to prevent nutrient depletion inside the $95 \mu \mathrm{m}$ filtered and control LCs (Bossard \& Uehlinger, 1988). Further details of experimental purposes and procedures are given by Bloesch \& Bürgi (1988) and Uehlinger \& Bloesch (1987a).

For determining vertical eddy diffusion the commonly use temperature method (Hutchinson, 1975) could not be applied, because the heat input through the plastic walls of the LCs is greater than that induced from the surface. We therefore introduced a biologically conservative tracer, either sodium chloride $(\mathrm{NaCl})$ or dye (rhodamine), into a separate $\mathrm{LC}$ and measured their vertical distribution in two day intervals. When $\mathrm{NaCl}$ had been added, the salt concentration was measured with an in situ conductivity recorder of high precision ('Oxytester'; Ambühl, 1960); the dye concentration was monitored by an in situ pulse light fluorometer ('Variosens II'; Uehlinger, 1985). The eddy diffusion coefficients were then calculated by an iteration computer programme (H. Bührer, unpublished). We assumed that these results can be extrapolated to the other LCs in which the ecological experiments were performed during the same time period.

Water samples at discrete depths and sediment trap samples in the experimental LCs were taken according to Uehlinger et al. (1984). Chemical analysis comprised total phosphorus (TP), soluble reactive phosphorus (SRP), particulate organic carbon (POC), and chlorophyll $a$ (chl.a) in the water, and dry weight (DW), particulate phosphorus (PP), $P O C$, and particulate nitrogen (PN) in the sediments, respectively, and were performed with current methods as described by Uehlinger et al. (1984). Primary production was measured with the ${ }^{14} \mathrm{C}$ acid bubbling method (Gächter \& Mares, 1979; Bossard \& Uehlinger, 1988). Daily primary production rates were calculated by the model of $\mathrm{H}$. Bührer (unpublished).

Both phytoplankton and zooplankton were sampled at 5 horizontally distributed sampling sites to equalize horizontal heterogeneities (Stephenson et al., 1984; Uehlinger et al., 1984). Integrated phytoplankton samples were taken with a $10 \mathrm{~m}$ long plastic tube of $1.1 \mathrm{~cm}$ diameter, and integrated zooplankton samples were taken with a quantitative $95 \mu \mathrm{m}$ net (ratio opening:area $=1: 50$; Bürgi, 1983). Phytoplankton and zooplankton were identified as living organisms and counted in preserved water and sediment samples. Phytoplankton and small protozoans were conserved in Lugol's solution and counted in an inverted microscope (Utermöhl, 1958). Larger protozoans and rotifers were concentrated by a factor of ten with a $30 \mu \mathrm{m}$ net (Dodson \& Thomas, 1978) prior to be counted by the 
Utermöhl-technique. Crustacean zooplankton were fixed with $4 \%$ formalin and counted in a stereo microscope. Biomass (fresh weight) was determined from the volumes of phytoplankton (Rott, 1981) and zooplankton (Bürgi \& Egli, 1984).

Phytoplankton was separated into four functional groups (Bürgi, 1988):

1. large, non-motile algae, such as pennate diatoms (>30 $\mu \mathrm{m}$ : netplankton);

2. large, motile algae, such as peridineae ( $>30 \mu \mathrm{m}$ : netplankton);

3. small, non-motile algae, such as small central diatoms ( $<30 \mu \mathrm{m}$ : nannoplankton);

4. small, motile algae, such as flagellates $(<30 \mu \mathrm{m}$ : nannoplankton).

Zooplankton was separated into macrozooplankton (crustaceans) and microzooplankton (rotifers and ciliates), and further subdivided according to their feeding behaviour into herbivores and carnivores.

\section{Results}

The results of our limnocorral (LC) experiments are summarized and illustrated in Fig. 1. Various parameters are compared between the $95 \mu \mathrm{m}$ filtered and control LC at the start (r) of the experiments and averaged $\left(r^{\prime}\right)$ over the two weeks of the experiments. The relationship of the ratios $r$ and $r^{\prime}$, plotted in Fig. 1, explains differences and temporal changes caused by biomanipulation. Thereby, three different groups of parameters should be distinguished:

a) crop parameters, such as POC, PP, chlorophyll $a$ and phytoplankton biomass allowing the assessment of the true start concentrations at the first
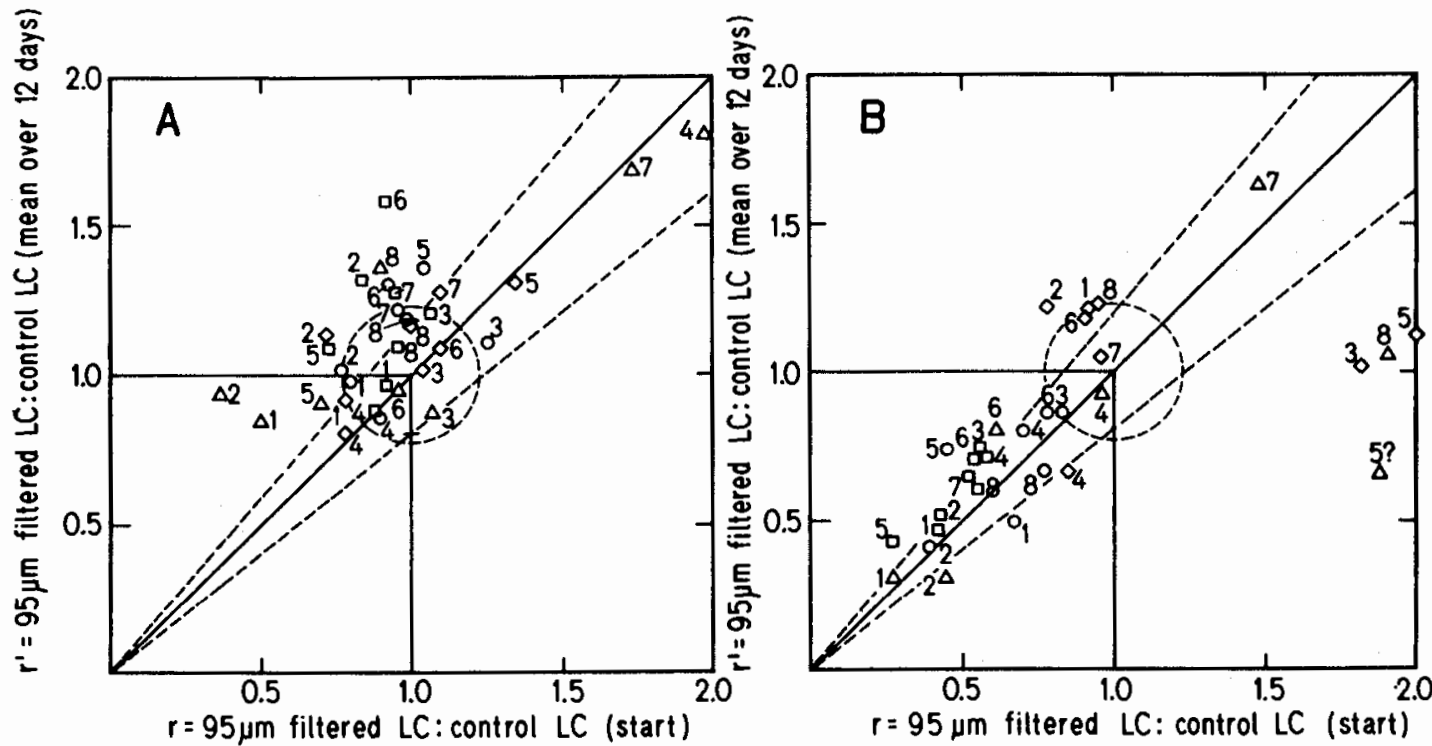

Fig. 1. Summarized results of eight limnocorral (LC) experiments performed in 1982-1984 in mesotrophic Lake Lucerne (Kastanienbaum), Switzerland. (Detailed data are published by Uehlinger \& Bloesch, 1987a, 1987b; Bloesch \& Bürgi, 1988; Bossard \& Uehlinger, 1988; Bürgi, 1988).

The ratio between the $95 \mu \mathrm{m}$ filtered LCs: control LCs for various parameters at the start of the experiments (r) is plotted against the same ratio for concentrations or flux averaged over the two week experiments $\left(r^{\prime}\right)$. The relationship $r \neq 1$ (initial change) and the regression $r \neq r^{\prime}$ (temporal change) are assumed to have a standard deviation of $\pm 20 \%$ as found for the variation of four identically treated LCs (Uehlinger et al, 1984).

A. POC concentration ( 0 ); PP concentration ( 0 ); chlorophyll $a$ concentration ( $\diamond)$; phytoplankton fresh weight biomass ( $\Delta$ ). B. POC settling flux ( $(0)$; PP settling flux (a); primary production rates $(\diamond)$; phytoplankton fresh weight settling flux $(\Delta)$. The numbers of the plotted data sets refer to the numbers of experiments as given in Table 1. 
day of the experiment. A ratio of $r=1$ indicates no difference between the filtered and control LC at the beginning of an experiment; however, a deviation $(r \neq 1)$ results, if the $95 \mu \mathrm{m}$ filtration during LC deployment would influence the seston concentrations. Different temporal changes in the filtered and control LC during the experiments, supposedly caused by zooplankton grazing, would be seen by deviations from the relationship $r=r^{\prime}$ (represented by the regression lines in Fig. 1), i.e. $r / r^{\prime} \neq 1$.

b) short-term flux parameters, such as primary production, yielding instantaneous information. If $r \not 1$, the deviation can also be explained by the mechanical manipulation (i.e. filtration artifact). If $r / r^{\prime} \neq 1$, the deviation is most likely caused by the biomanipulation (removal of zooplankton grazing pressure).

c) long-term flux parameters, such as sedimentation measured in 4 day intervals, where $r$ does not reflect the true start conditions. A deviation from $r=1$ means that the system reacts very quickly to biomanipulation, i.e. within at least 4 days in our experiments. A deviation from $r / r^{\prime}=1$ would indicate a different temporal change of settling flux in the filtered and control LC.

Figure 1A shows that the seston concentrations were generally similar in both LCs at the beginning of the experiments $(\mathrm{r} \sim 1)$; however, during the experiments they were depressed in the control LCs when compared to the $95 \mu \mathrm{m}$ filtered LCs $\left(r^{\prime}>1 ; r / r^{\prime}<1\right)$. In contrast, Fig. 1B shows that the sedimentation flux was distinctly larger in the control LCs than in the $95 \mu \mathrm{m}$ filtered LCs throughout the experiments $\left(\mathrm{r}<1 ; \mathrm{r}^{\prime}<1 ; \mathrm{r} / \mathrm{r}^{\prime} \sim 1\right)$. The biomass parameters (phytoplankton standing crop, Fig. 1A; phytoplankton sedimentation and primary production, Fig. 1B) showed significant aberrations in some experiments. This is caused by a large inherent variability of biological parameters rather than by methodological and analytical errors. Therefore, the biological data are less reliable than chemical data and must be interpreted with great caution.

In general, the zooplankton grazing activity in the control LCs reduced the sestonic POC and PP (Fig. 1A), and partly the primary production (Fig. 1B). However, $\mathrm{C}$ and $\mathrm{P}$ regeneration were not significantly affected (Bossard \& Uehlinger, 1988), which shows that complex ecosystems react like selfregulating 'buffered' systems when they are disturbed. The C:P ratios of seston were similar in both LCs, whereas the C:P ratios of entrapped particulate material were slightly decreased in the control LCs containing the large zooplankton (Uehlinger \& Bloesch, 1987a). The crustaceans ingesting mainly nannoplankton (Bürgi, 1988) excreted large fecal aggregates, and this particle transformation caused the increase of sedimentation rates (Uehlinger \& Bloesch, 1987b; Bloesch \& Bürgi, 1988). Moreover, a shift from nannoplankton to netplankton (Fig. 2) stimulated sedimentation, because the latter has greater sinking velocities and robust cells resistent to decomposition. However, since we observed this shift in both LCs, it could not be attributed to the presence of zooplankton, but rather could have been caused by $\mathrm{P}$ fertilization and subsequent nutrient competition between algae favouring the netplankton (Bürgi, 1988), or could have been an artifact caused by the diminished turbulence inside the LCs.

The eddy diffusion as an indicator of turbulence was measured inside a special LC in each experiment

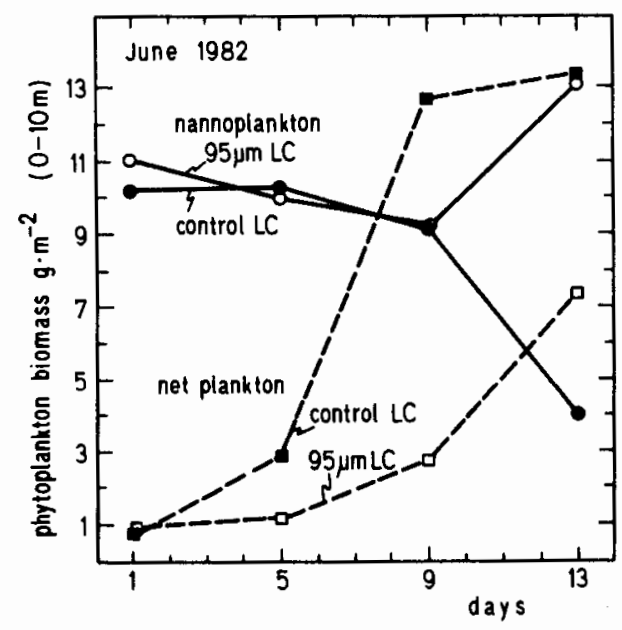

Fig. 2. Changes of phytoplankton biomass composition during a representative LC experiment in June 1982 (No. 82/2). The relative amount of nannoplankton $(<30 \mu \mathrm{m})$ dropped from $94 \%$ at the beginning to $64 \%$ in the $95 \mu \mathrm{m}$ filtered LC and to $23 \%$ in the control LC, whereas netplankton $(>30 \mu \mathrm{m})$ increased from $6 \%$ to $36 \%$ and $77 \%$, respectively. Similar shifts from nannoplankton to netplankton were observed in all LCs except in the control LC of experiment $83 / 2$ (Bloesch \& Bürgi, 1988). 
by using $\mathrm{NaCl}$ or dye, and the results presented in Table $2 \mathrm{~A}$ were compared with lake data from the literature (Table 2B). The methods did not yield exactly the same results, as the dye-method was more sensitive: the dye could be applied in low concentrations at $4 \mathrm{~m}$ depth and the vertical diffusion could be tracked in the upward and downward direction. The salt had to be applied in higher concentrations so that a density layer formed at the bottom of the LCs; thus, the vertical diffusion of $\mathrm{NaCl}$ could only be tracked in the upward direction, and the concentration gradients became progressively smaller towards the surface, where they were in the range of the error of the conductivity measurement. Hence, both negative and unreliably high $\mathrm{K}_{\mathrm{z}}$ values were obtained in $43 \%$ of all calculations. We therefore do not recom- mend the use of the NaCl-method, although we can get reasonable results by discarding the negative values and erratic positive values (here arbitrarily defined as $>0.5 \mathrm{~cm}^{2} \cdot \mathrm{s}^{-1}$ and rising up to $19 \mathrm{~cm}^{2} \cdot \mathrm{s}^{-1}$ ). The rhodamine-method was more reliable and yielded a mean eddy diffusion coefficient of $0.1 \mathrm{~cm}^{2} \cdot \mathrm{s}^{-1}$ inside the LCs. Considering the fact that the dye-method may slightly overestimate vertical eddy diffusion (Hesslein \& Quay, 1973), our results were at least 1 order of magnitude smaller than results obtained in the epilimnion of lakes (Table $2 \mathrm{~B}$ ).

To evaluate the transfer of our results (presented in Fig. 1) to in situ conditions, we compared available lake data with data obtained in the LCs (Tables $3-5$ ). The phytoplankton and zooplankton biomass

Table 2A. Eddy diffusion coefficients $\mathrm{K}_{\mathrm{Z}}\left(\mathrm{cm}^{2} \cdot \mathrm{s}^{-1}\right)$ in limnocorrals. Data from $\mathrm{H}$. Bührer (unpublished).

\begin{tabular}{lllr}
\hline Experiment No. & Tracer used & Depth & $\mathrm{K}_{\mathrm{Z}}\left(\mathrm{cm}^{2} \cdot \mathrm{s}^{-1}\right)$ \\
\hline $82 / 2$ & $\mathrm{NaCl}^{*}$ & $1-3 \mathrm{~m}$ & $0.24 \pm 0.128(0.095-0.469)$ \\
& & $4-8 \mathrm{~m}$ & $0.17 \pm 0.102(0.043-0.336)$ \\
& & $9-10 \mathrm{~m}$ & $0.008 \pm 0.006(0.002-0.023)$ \\
$83 / 1$ & $\mathrm{NaCl}^{*}$ & $1-3 \mathrm{~m}$ & $0.21 \pm 0.154(0.049-0.460)$ \\
& & $4-7 \mathrm{~m}$ & $0.20 \pm 0.037(0.157-0.239)$ \\
$83 / 2$ & & $8-10 \mathrm{~m}$ & $0.003 \pm 0.003(0.001-0.012)$ \\
& $\mathrm{NaCl}^{*}$ & $1-2 \mathrm{~m}$ & $0.14 \pm 0.001(0.138-0.139)$ \\
& & $2-10 \mathrm{~m}$ & $0.08 \pm 0.118(0.003-0.423)$ \\
& Rhodamine & $1-3 \mathrm{~m}$ & $0.13 \pm 0.077(0.089-0.330)$ \\
$83 / 3$ & & $4-10 \mathrm{~m}$ & $0.07 \pm 0.058(0.019-0.229)$ \\
& Rhodamine & $1 \mathrm{~m}$ & $(0.07-0.50)$ \\
& & $5 \mathrm{~m}$ & $(0.03-0.07)$ \\
& & $6-10 \mathrm{~m}$ & $(0.06-0.12)$
\end{tabular}

*Negative and erratic positive values $\left(>0.5 \mathrm{~cm}^{2} \cdot \mathrm{s}^{-1}\right)$ were discarded, as these originated from low salt concentrations in the sensitivity range of the method.

Table $2 B$. Eddy diffusion coefficients $\mathrm{K}_{\mathrm{Z}}\left(\mathrm{cm}^{2} \cdot \mathrm{s}^{-1}\right)$ in lakes.

\begin{tabular}{lllll}
\hline Lake & Limnion & Depth & Mean $\mathrm{K}_{\mathrm{Z}}\left(\mathrm{cm}^{2} \cdot \mathrm{s}^{-1}\right)$ & Literature \\
\hline Huron & epi & $0-2 \mathrm{~m}$ & 7.0 & Csanady, 1964 \\
Erie & epi & $0-2 \mathrm{~m}$ & 3.0 & Csanady, 1964 \\
Maggiore & epi & - & 1.0 & Barbanti \& Carollo, 1967 \\
Lucerne & meta & $6-8 \mathrm{~m}$ & $0.056^{*}$ & O'Melia, 1972 \\
Lucerne & meta & $15 \mathrm{~m}$ & $0.10-1.58^{*}$ & Bloesch et al., 1977 \\
\hline
\end{tabular}

*No data available from epilimnion of Lake Lucerne; $\mathrm{K}_{\mathrm{Z}}$ in the metalimnion can be estimated to at least one order of magnitude smaller than in the mixed epilimnion. 
Table 3. Phytoplankton and zooplankton biomass in control limnocorrals (LCs) and in the surrounding lake. Values in $\mathrm{g}$ fresh weight $\cdot \mathrm{m}^{-2}(0-10 \mathrm{~m})$.

\begin{tabular}{|c|c|c|c|c|c|c|c|c|}
\hline \multirow{2}{*}{$\begin{array}{l}\text { Experiment } \\
\text { No. }\end{array}$} & \multirow[t]{2}{*}{ Time period } & \multirow{2}{*}{$\begin{array}{l}\text { Lake } \\
\text { Sampling date }\end{array}$} & \multicolumn{2}{|c|}{ Zooplankton (Z) } & \multicolumn{2}{|c|}{ Phytoplankton (P) } & \multicolumn{2}{|c|}{ Ratio $\mathrm{Z} / \mathrm{P}$} \\
\hline & & & $\mathrm{LC}^{*}$ & Lake & $\mathbf{L C} *$ & Lake & $\mathrm{LC}^{*}$ & Lake \\
\hline $82 / 1 \mathrm{~A}$ & $25 \mathrm{Mar}-6 \mathrm{Apr}$ & $31 \mathrm{Mar}$ & $5.8 \pm \quad 1.0$ & 54.9 & $10.3 \pm 2.5$ & 43.9 & 0.6 & 1.3 \\
\hline $82 / 2$ & $17-29$ Jun & 22 Jun & $83.6 \pm 112$ & 69.2 & $15.9 \pm 4.8$ & 10.5 & 5.3 & 6.6 \\
\hline $83 / 1$ & 17-29 Mar & 7 Mar \& 5 Apr & $11.3 \pm \quad 3.2$ & 57.5 & $17.8 \pm 6.0$ & 22.3 & 0.6 & 2.6 \\
\hline $83 / 2$ & 26 May - 7 Jun & 4 May \& 6 Jun & $61.1 \pm 33$ & 99.8 & $7.1 \pm 5.2$ & 21.8 & 8.6 & 4.6 \\
\hline $83 / 3$ & $30 \mathrm{Jun}-2 \mathrm{Jul}$ & $5 \mathrm{Jul}$ & $21.2 \pm \quad 5.8$ & 84.2 & $6.6 \pm 1.6$ & 23.6 & 4.0 & 3.6 \\
\hline $84 / 1 \mathrm{~A}$ & 24 May - 5 Jun & 14 May \& 18 Jun & $22.2 \pm 13.3$ & 74.0 & $1.0 \pm 0.5$ & 10.8 & 18.3 & 6.9 \\
\hline $84 / 1$ B & same & same & $12.6 \pm \quad 6.0$ & 74.0 & $1.0 \pm 0.5$ & 10.8 & 12.6 & 6.9 \\
\hline
\end{tabular}

*Mean values over two weeks (4-10 samples).

(fresh weight) inside the control LCs was smaller than in the lake, except for experiment $82 / 2$ (Table 3). In two experiments $(82 / 1 \mathrm{~A}, 83 / 1)$ the ratio of zooplankton/phytoplankton biomass was smaller than 1, whereas in all other situations the zooplankton dominated the phytoplankton. These figures must be interpreted with caution, since patchiness, vertical and horizontal movement of plankton may influence the lake communities to a greater extent than enclosed communities, and as the sampling dates and times were not exactly the same for the LCs and the lake. However, the LCs seem to have a tendency to diminish the plankton biomass to some ex- tent. This could have been caused either during the LC deployment, or by the different dynamics in the relatively closed system during the course of the experiment.

More detailed zooplankton data from the experiments 84/1 (Table 4) allowed us to check the problem of vertical migration of crustaceans. It is expected that the zooplankton concentrations measured in the epilimnion $(0-10 \mathrm{~m})$ are in part dependent on the sampling time, as diurnal crustacean migration takes place. In the first half of the experiment (26-30 May), the zooplankton biomass was below $10 \mathrm{~g} \cdot \mathrm{m}^{-2}$ in the lake and in the LCs. The sampling

Table 4. Crustacean zooplankton standing crop (fresh weight; $\mathrm{g} \cdot \mathrm{m}^{-2}$ ) in the epilimnetic layer of $0-10 \mathrm{~m}$ in limnocorrals and in the lake. May - June, 1984.

\begin{tabular}{|c|c|c|c|c|}
\hline Day & Sampling time & $\begin{array}{l}\text { Lake offshore } \\
70 \mathrm{~m} \text { deep }\end{array}$ & $\begin{array}{l}\text { Lake nearshore } \\
\sim 18 \text { m deep }\end{array}$ & Control LC \\
\hline \multirow[t]{2}{*}{26 May } & $06.30 \mathrm{pm}$ & - & 8.18 & 2.55 \\
\hline & $09.00 \mathrm{pm}$ & - & - & 2.22 \\
\hline \multirow[t]{2}{*}{27 May } & $00.30 \mathrm{am}$ & - & - & 6.75 \\
\hline & $05.00 \mathrm{am}$ & - & - & 4.73 \\
\hline \multirow[t]{2}{*}{29 May } & $03.30 \mathrm{pm}$ & 2.25 & - & - \\
\hline & $08.00 \mathrm{pm}$ & - & - & 12.17 \\
\hline \multirow[t]{3}{*}{30 May } & $00.30 \mathrm{am}$ & 7.80 & - & - \\
\hline & $04.30 \mathrm{am}$ & - & - & 7.84 \\
\hline & $07.30 \mathrm{am}$ & - & - & 9.90 \\
\hline \multirow[t]{4}{*}{5 June } & $04.30 \mathrm{pm}$ & 99.75 & 40.43 & 30.19 \\
\hline & $07.00 \mathrm{pm}$ & 104.63 & 60.04 & 21.82 \\
\hline & $09.00 \mathrm{pm}$ & 183.78 & 60.46 & 29.08 \\
\hline & $11.30 \mathrm{pm}$ & 178.70 & 132.86 & 46.68 \\
\hline
\end{tabular}


Table 5. Dry weight (DW), POC and PP sedimentation rates $\left(\mathrm{mg} \cdot \mathrm{m}^{-2} \cdot \mathrm{d}^{-1}\right)$ in limnocorrals and in the nearby lake. May - June, 1984.

\begin{tabular}{|c|c|c|c|c|c|c|c|c|c|}
\hline \multirow[t]{2}{*}{ Time period } & \multicolumn{3}{|c|}{$\begin{array}{l}95 \mu \mathrm{m} \text { filtered LCs, mean of } 2 \\
\text { differently fertilized LCs }\end{array}$} & \multicolumn{3}{|c|}{$\begin{array}{l}\text { Control LCs, mean of } 2 \\
\text { differently fertilized LCs }\end{array}$} & \multicolumn{3}{|c|}{ Lake, near LCs } \\
\hline & DW & POC & $\mathrm{PP}$ & DW & POC & PP & DW & POC & PP \\
\hline $24-28$ May & 779 & 113 & 1.45 & 855 & 178 & 2.72 & 1319 & 160 & 3.34 \\
\hline 28 May - 1 June & 1045 & 153 & 2.56 & 1185 & 199 & 4.02 & 1569 & 139 & 3.25 \\
\hline $1-5$ June & 1911 & 286 & 4.65 & 2463 & 456 & 7.00 & 2516 & 212 & 4.42 \\
\hline$\Sigma 12$ days & 14940 & 2208 & 34.64 & 18012 & 3332 & 54.96 & 21616 & 2044 & 44.04 \\
\hline
\end{tabular}

time seemed not to influence these figures, which is indicative of negligible vertical migration. In the second half of the experiment (5 June), when the zooplankton were much more abundant, we found differences in zooplankton biomass with reference to the sampling site and sampling time as well. The highest crustacean biomass was measured in the lake offshore, whereas the nearshore biomass amounted to only $52 \%$ of that offshore. In the control LC, the zooplankton biomass was further decreased to $23 \%$ and $44 \%$, respectively, of the offshore and nearshore biomass. In addition, the lake biomass increased during the night of 5 June by a factor of $2-3$, whereas these differences were minor in the control LC. The increased biomass offshore and the distinct short-term variation can be explained by the large potential of animals resting in deeper zones during the day and their vertical upward migration during the night. Although this phenomenon is also present nearshore, it is restricted to a much smaller depth, and therefore the zooplankton concentration is smaller when compared to the offshore biomass. The small fluctuations inside the LCs at the same time indicate only limited migration, as few animals escape temporarily to the lowest sections of the LCs; however, no additional potential is available, as the system is closed.

Finally, we compared the settling flux inside the LCs with that of the lake outside the LCs (Table 5). During this time period we found an increase in sedimentation inside as well as outside the LCs. However, there was a quantitative difference: while DW settling flux increased 1.9 times, and POC and PP flux 1.3 times in the lake, this increase was 2.9 times for DW flux and 2.6 times for POC and PP flux, respectively, in the control LCs. The total DW settling flux (over 12 days) was diminished by $17 \%$ in the control LCs when compared to the lake, however, the total POC and PP settling fluxes were increased by $64 \%$ and $25 \%$, respectively. These differences may have been caused by diminished vertical turbulence (increasing sedimentation of epilimnetic autochthonous material) and inhibited bottom sediment resuspension (decreasing sedimentation of resuspended material) inside the LCs.

\section{Discussion}

The limnocorral (LC) technique is well suited methodologically for many purposes such as testing limiting nutrients and toxic substances (Gächter, 1968; Bürgi, 1974; CEPEX, 1977; MELIMEX, 1979). Such experiments of the cause-effect type result in net changes of the biological system and do not elucidate single pathways of the complex ecological network. On the other hand, LCs can also be used for biomanipulation studies to investigate ecologically relevant fluxes such as primary production, nutrient regeneration, zooplankton grazing, sedimentation and the interrelationships thereof (Bürgi et al., 1979). Three types of problems are of concern when LC experiments are performed to study the structure and function of lake ecosystems: Firstly, the replicability of LC experiments should be checked; secondly, we should deal with both the size scale of LCs and the time scale of such experiments; and thirdly, we may optimize the experimental setup 
and performance to allow direct extrapolation of results from LC experiments to in situ conditions.

\section{Replicability of LC experiments}

Experiments with LCs face a serious dilemma: the closer to nature the enclosed mesocosms the worse they replicate, because the stochastic behaviour is inherent in complex ecosystems (Pilson \& Nixon, 1980). However, the statistical validity of results obtained from such experiments is an important criterion for the applicability of this method. That replicate LCs can behave similarly has been proven by different authors (Takahashi, 1975; MELIMEX, 1979). We have shown in preliminary two weeks experiments (1981) that static parameters (i.e. change of seston concentrations) and dynamic parameters (i.e. fluxes) in four identically treated LCs showed coefficients of variation in the range of $\pm 20 \%$, if sampling strategies were optimized (Uehlinger et al., 1984). Although considered reasonable for a complex ecosystem, this variation occurring from both horizontal heterogeneities and analytical errors limits the sensitivity of the LC method: Differences caused by biomanipulation are only significant, if the variance between differently treated LCs exceeds the variance between replicates, i.e. $\sim 20 \%$ in our LCs. (Since manpower and costs were limited, it was impossible to run replicate LCs in the biomanipulation experiments performed in 1982-1984.) This $20 \%$ limit of variance was quite frequently exceeded by both the static and the dynamic parameters (see Fig. 1) giving statistical confidence to the decrease in seston concentration and the increase in settling flux occurring in the control LCs. This was proven by statistical analysis of the data set (Table 6) showing again that the effect of zooplankton on chl. $a$, phytoplankton, and primary production was surprisingly small when compared to POC and PP. Moreover, looking at all experiments we always found outliers, and hence one single experiment may easily lead to wrong conclusions. Unfortunately, we have no explanations at hand to declare an experiment as 'erratic'. Our LCs were designed as complex systems, and thus many parameters such as bacteria could explain the observed development but were not investigated.

\section{2a. Size scale of $L C s$}

The question of how LCs should be disigned to avoid or limit artifacts is closely related to their size (Maguire et al., 1980; Harte et al., 1980; Adler et al., 1980 ) and to the purpose of the investigation (Pilson \& Nixon, 1980). Since the aim of our experiments was to study the epilimnetic $\mathrm{C}$ and $\mathrm{P}$ cycles, we adjusted the length of our LCs to the depth of both the thermocline and the light extinction. Also, we optimized the ratio 'volume: lateral (plastic) surface' by increasing the diameter from $1 \mathrm{~m}$ in LCs used in earlier experiments (Bürgi et al., 1979) to $3 \mathrm{~m}$ in the LCs used in this study. The volume of $-70 \mathrm{~m}^{3}$ seemed to be large enough to provide a near-natural ecosystem. However, the behaviour of our enclosed mesocosm was most seriously affected by the reduction of turbulence (Table 2), the consequence thereof will be discussed below. Applying criteria of similarity as used in hydraulics (Platt et al., 1981), the size of an appropriate epilimnetic mesocosm would imply a diameter in the order of the typical eddies occurring in the lake where they are exposed. Since the spectrum of horizontal eddies extends over the size of the lake basin down to the smallest turbulent structures limited by the energy dissipation by friction, any enclosure will change the natural mixing pattern. Thus it is virtually impossible to avoid changes in turbulence inside of LCs, unless complicated flow-through systems or mixing simulations are used (Imboden et al., 1979; Nixon et al., 1980). We realize the extreme difficulties to achieve near-natural turbulance patterns inside of LCs. An intercomparison study measuring eddies in the lake and in a series of LCs of variable size and design could help to overcome the problems. At the present knowledge, we recommend the use of large LCs for ecological studies, although technical and financial problems may occur.

\section{2b. Time scale of $L C$ experiments}

The optimal duration of LC experiments is closely linked with the objective of the investigation, but should also be adjusted to the size of the system enclosed. Macrocosms ( $>1000 \mathrm{~m}^{3}$ ) may well be suited for studying ecotoxicology or population dynam- 
Table 6. Statistical test of differences between $95 \mu \mathrm{m}$ filtered and unfiltered (control) LCs from 8 experiments as given in Table 1 . The Wilcoxon matched pairs signed ranks test was used: s. = significant difference (in brackets: level of significance), $n . s$. = no significant difference (compare with $20 \%$ variance circle in Fig. 1).

$\mathrm{r}=\frac{95 \mu \mathrm{m} \text { filtered LC }}{\text { control LC }}$ (start) $r^{\prime}=\frac{95 \mu \mathrm{m} \text { filtered LC }}{\text { control LC }}$ (mean over 12 days)

\begin{tabular}{|c|c|c|c|}
\hline Parameter & $\mathbf{r}$ & $\mathbf{r}^{\prime}$ & $r / r^{\prime}$ \\
\hline \multicolumn{4}{|l|}{ A. Seston concentration } \\
\hline expected & -1 (n.s.) $)^{1}$ & $>1(\text { s. })^{2}$ & $<1$ ( s.) \\
\hline measured PP & s. $(5 \%)$ & s. $(5 \%))^{*}$ & s. $(1 \%)$ \\
\hline POC & n.s. & s. $(5 \%)^{*}$ & s. $(5 \%)$ \\
\hline Chl.a & n.s. & n.s. & n.s. \\
\hline phytoplankton fresh weight & n.s. & n.s. & n.s. \\
\hline \multicolumn{4}{|l|}{ B. Short-term flux } \\
\hline expected & $\sim 1$ (n.s.) $)^{1}$ & $\geq 1$ (n.s.) $)^{3}$ & $\sim 1$ (n.s.) \\
\hline measured primary production & n.s. & s. $(5 \%)^{*}$ & n.s. \\
\hline \multicolumn{4}{|l|}{ C. Long-term settling flux } \\
\hline expected & $<1(\text { s. })^{4}$ & $<1(\text { s. })^{4}$ & $\sim 1$ (n.s.) \\
\hline measured PP & s. $(1 \%)$ & s. $(1 \%)$ & s. $(1 \%)$ \\
\hline POC & s. $(1 \%)$ & s. $(1 \%)$ & n.s. \\
\hline phytoplankton fresh weight & n.s. & n.s. & n.s. \\
\hline
\end{tabular}

*1 outlier discarded; n.s. if all experiments respected.

1 No effect through $95 \mu \mathrm{m}$ filtration at the start of the experiments.

${ }^{2}$ Seston decrease in control LCs during the experiments.

${ }^{3}$ No effect or small decrease in control LCs during the experiments.

${ }^{4}$ Sedimentation increase in control LCs during the experiments.

ics over months and years (MELIMEX, 1979; Reynolds, 1986). Microcosms ( $<1 \mathrm{~m}^{3}$ ) suffer from the loss of volume sampled, and wall effects such as attached growth. The duration of our mesocosm experiments was restricted to two weeks, because attached growth (taking up nutrients and getting loose when mature) would have significantly interfered with our measurements and calculations of $C$ and $P$ fluxes, if the experimental time would have been extended (see Uehlinger et al., 1984, Table 2). However, our experiments yielded short-term fluctuations in both phytoplankton and zooplankton (Bloesch \& Bürgi, 1988; Bürgi, 1988), but these may not reflect long-term changes in the lake. This was of less importance, since we aimed to study the ecological role of crustacean zooplankton in the epilimnetic $\mathrm{C}$ and $P$ cycles, rather than to study long-term effects of biomanipulation as used for lake restoration (Edmondson, 1979; Shapiro et al., 1982). But neverthe- less, the discrepancy between mesocosm and lake makes extrapolation more difficult.

\section{Extrapolation of results from $L C$ experiments}

Complex aquatic communities are sensitive to environmental changes. Thus, the similarity of the plankton composition and succession inside the control LC and the surrounding lake is an important criterion for data extrapolation. We may not be able, however, to achieve the desired degree of similarity because of the inherent stochastic nature of these systems (Table 3). Differences in plankton dynamics between the mesocosm and the lake may be caused either by different conditions at the start of an experiment, and/or by persistent changes in environmental conditions in the isolated LC during an experiment. 
Whereas in each single experiment the start conditions for the LCs were quite similar (except for the manipulated zooplankton), the start conditions altered significantly between the different experiments, according to the year and season. The range of start concentrations found in control LCs was 2.9-11.4 $\mathrm{g} \cdot \mathrm{m}^{-2}$ for particulate organic carbon (POC), 44-292 $\mathrm{mg} \cdot \mathrm{m}^{-2}$ for particulate phosphorus (PP), $2-97 \mathrm{mg} \cdot \mathrm{m}^{-2}$ for soluble reactive phosphorus (SRP), $0.9-28.3 \mathrm{~g} \cdot \mathrm{m}^{-2}$ for total phytoplankton biomass (fresh weight), and 4.5-93.2 $\mathrm{g} \cdot \mathrm{m}^{-2}$ for total zooplankton biomass (fresh weight) (Bloesch \& Bürgi, 1988). Hence, the course of an experiment was supposedly influenced by the actual situation in the lake at the beginning of an experiment. This made an intercomparison between experiments difficult (see Fig. 1).

During the experiment the phytoplankton was less abundant (Table 3), and POC and PP sedimentation rates were increased (Table 5), when compared to the surrounding lake. The significant reduction of the vertical eddy diffusion (by a factor of $\sim 10$ ) caused these systematic differences between the control LC and the lake. In addition, the plastic walls prevented horizontal advection and allochthonous nutrient supply, which, however, was compensated by phosphate fertilization. Since simulation of natural $\mathbf{P}$ supply is extremely difficult, the fertilization regimes applied may have favoured the larger algae. This would explain the shift from nannoplankton to netplankton, observed with and without herbivorous zooplankton enclosed (Fig. 2). Finally, the closed bottom of our LCs limited vertical migration of herbivorous crustaceans (Table 4), thus enabling grazing over 24 hours. In the lake, however, most of the zooplankton grazing takes place during the night (Lampert et al., 1986; Angehrn, 1986).

In summary, our LCs showed some significant differences to the lake conditions enabling different patterns of development. Although these experiments did not allow a very detailed quantitative interpretation of results, we did find a significant impact of zooplankton on particulate material. The presence of crustacean zooplankton reduced the seston by grazing and enhanced particle sedimentation by fecal pellet formation. There is no reason against extrapolating these findings to the lake on a qualitative basis; however, we cannot extrapolate the quantitative impact of zooplankton.

\section{Summary and conclusions}

In situ studies (e.g. LCs), laboratory experiments (e.g. algal cultures), and field investigations in lake systems are all necessary and complementary approaches to ecological problems. In large lakes biomanipulation experiments cannot be performed, but LCs provide a practical alternative. The use of mesocosms, however, is linked with problems of scaling. With respect to the complexity of the enclosed system, our LCs containing $70 \mathrm{~m}^{3}$ of lake water were much closer to lake conditions than to laboratory cultures. However, deviations of control LCs from the lake were caused by the relative small size of the enclosures preventing horizontal advection and decreasing vertical eddy diffusion. These physical changes, and the $P$ fertilization applied, influenced phytoplankton succession, favoured netplankton and increased seston sedimentation.

Although biomanipulation experiments performed in LCs should always be viewed with regard to the fact that whole lake ecosystems may behave differently, this technique was succesful to study the influence of crustacean zooplankton on the epilimnetic $C$ and $P$ fluxes. Their particle transformation and subsequent increase of sestonic settling flux, as well as their limited influence on $C$ and $P$ regeneration can be extrapolated on a qualitative basis.

\section{Acknowledgements}

The financial support of EAWAG for this large project is acknowledged. We thank $H$. Bachmann, P. Binz, B. Egli, H. J. Fricker, J. Gavrieli, B. Germann, R. Illi, B. Jäckli, R. Riederer, B. Ribi, A. Stöckli, E. Szabo and P. Wili for providing technical assistance. God bless Modecia Minor, whose spirit was hovering above the LCs! 


\section{References}

Ambühl, H., 1960. Die praktische Anwendung der elektrochemischen Sauerstoffbestimmung im Wasser. Schweiz. Z. Hydrol. 12: 23-39.

Adler, D., M. Amdurer \& P. H. Santschi, 1980. Metal Tracers in Two Marine Microcosms: Sensitivity to Scale and Configuration. In J. P. Giesy, Jr. (ed.), Microcosms in ecological research. Tech. Info. Center U.S. Dept. of Energy: 348-368.

Angehrn, J., 1986. Micro- and macrozooplankton grazing on nannoplankton in a eutrophic lake, with special attention to the rotifer Keratella cochlearis. Diss. ETH Nr. 7858.

Barbanti, L. \& A. Carollo, 1967: Analisi della diffusione turbolenta e dei processi circolatori nel Lago Maggiore con l'impiego di un tracciante fluorescente. Mem. Ist. ital. Idrobiol. 21: $37-87$.

Bloesch, J. \& H. R. Bürgi, 1988. Changes in phytoplankton and zooplankton biomass and composition reflected by sedimentation. (Biomanipulation in Limnocorrals III). Limnol. Oceanogr., submitted.

Bloesch, J., P. Stadelmann \& H. Bührer, 1977. Primary production, mineralization, and sedimentation in the euphotic zone of two Swiss lakes. Limnol. Oceanogr. 22: 511-525.

Bossard, P. \& U. Uehlinger, 1988. The effect of herbivorous zooplankton and phosphate addition on epilimnetic carbon and phosphorus fluxes. (Biomanipulation in Limnocorrals IV). Limnol. Oceanogr., submitted.

Bürgi, H. R., 1974. Die Wirkung von NTA auf das Wachstum des Phytoplanktons unter besonderer Berücksichtigung des Eisens als Mikroelement. Schweiz. Z. Hydrol. 36: 1-70.

Bürgi, H. R., 1983. Eine neue Netzgarnitur mit KippSchliessmechanismus für quantitative Zooplanktonfänge in Seen. Schweiz. Z. Hydrol. 45: 505-507.

Bürgi, H. R., 1988. The influence of crustacean zooplankton variation on the phytoplankton. (Biomanipulation in Limnocorrals V). Int. Rev. ges. Hydrobiol.: submitted.

Bürgi, H. R., H. Bührer, J. Bloesch \& E. Szabo. 1979. Der Einfluss experimentell variierter Zooplanktondichte auf die Produktion und Sedimentation im hocheutrophen See. Schweiz. Z. Hydrol. 41: $38-63$.

Bürgi, H. R. \& B. Egli, 1984. Crustaceen-Plankton des Vierwaldstättersees. Grössenfraktionierung und Abundanzdynamik in den Jahren 1976 bis 1979. Schweiz Z. Hydrol. 46: 247-268.

Cembella, A. D., N. J. Antia \& P. J. Harrison, 1984. The utilization of inorganic and organic phosphorous compounds as nutrients by eukaryotic microalgae: A multidisciplinary perspective: part 1, CRC Critical Reviews in Microbiology, 10, 317-391; part 2, CRC Critical Reviews in Microbiology, 11, $13-81$.

CEPEX, 1977. Controlled ecosystem pollution experiment. (Various titles and authors). Bull. Mar. Sci. 27: 1-145.

Csanady, G. T., 1964. Turbulence and diffusion in the Great Lakes. Publ. Great Lakes Res. Div. No. 11, 326-329.

DeMott, W. R., 1982. Feeding selectivities and relative ingestion rates of Daphnia and Bosmina. Limnol. Oceanogr. 27: $518-527$.
Dodson, A. N. \& W. H. Thomas, 1978. Reverse filtration. In: A. Sournia (ed.), Monogr. Oceanogr. Methodol. 6, UNESCO, Paris: phytoplankton manual, pp. 104-107.

Edmondson, W. T., 1979. Lake Washington and the predictability of limnological events. Arch. Hydrobiol. Beih. Ergebn. Limnol. 13: 234-241.

Gächter, R., 1968. Phosphorhaushalt und planktische Primärproduktion im Vierwaldstättersee (Horwer Bucht). Schweiz. Z. Hydrol. 30: 1-66.

Gächter, R. \& A. Mares, 1979. Comments to the acidification and bubbling method for determining phytoplankton production. Oikos 33: 69-73.

Gächter, R. \& J. Urech, '1983. Feasibilities and limits of field experiments to study ecological implications of heavy metal pollution. In G. G. Leppard (ed.), Trace element speciation in surface waters and its ecological implications. Plenum Publ. Corp.: $137-158$.

Giesy Jr., J. P., 1980. Microcosms in ecological research. Selected papers from a symposium held at Augusta, Georgia, Nov 8-10, 1978. CONF-781101, Tech. Info. Center U.S. Dept. of Energy, $1110 \mathrm{pp}$.

Gliwicz, Z. M., 1980. Filtering rates, food size selection and feeding rates, in cladocerans - Another aspect of interspecific competition in filter-feeding zooplankton. Am. Soc. Limnol. Oceanogr. Spec. Symp. 3: 282-291. Univ. Press New England.

Grice, G. D. \& M. R. Reeve, 1982. Marine mesocosms. Biological and chemical research in experimental ecosystems. Springer, N.Y., 430 pp.

Haney, J. F. \& D. J. Hall, 1975. Diel vertical migration and filterfeeding activities of Daphnia. Arch. Hydrobiol. 75: $413-441$.

Harte, J., D. Levy, J. Rees \& E. Saegebarth, 1980. Making microcosms an effective assessment tool. In J. P. Giesy Jr. (ed.), Microcosms in ecological research. Tech. Info. Center U.S. Dept. of Energy: 105-137.

Hesslein, R. \& P. Quai, 1973. Vertical eddy diffusion studies in the thermocline of a small stratified lake. J. Fish. Res. Board Can. 30: 1491-1500.

Hutchinson, G. E., 1975. A treatise on limnology, 1. J. Wiley \& Sons, N.Y., 1015 pp.

Imboden, D. M., B. S. F. Eid, T. Joller, M. Schurter \& J. Wetzel, 1979. MELIMEX, an experimental heavy metal pollution study: Vertical mixture in a large limno-corral. Schweiz. Z. Hydrol. 41: 177-189.

Lampert, W., W. Fleckner, H. Rai \& B. E. Taylor, 1986. Phytoplankton control by grazing zooplankton: A study on the spring clear-water phase. Limnol. Oceanogr. 31: 478-490.

Lean, D. R. S. \& M. N. Charlton, 1976. A study of phosphorus kinetics in a lake ecosystem. In Environmental Biogeochemistry, Carbon, Nitrogen, Phosphorus, Sulfur and Selenium Cycles, Vol. 1, Nriagu, J. O., Ed., Ann Arbor Sci. Publ., 283-294.

Lund, J. W. G., 1972. Preliminary observations on the use of large experimental tubes in lakes. Verh. int. Ver. Limnol. 18: 71-77.

Maguire, B., Jr., L. B. Slobodkin, J. J. Morowitz, B. Moore III, \& D. B. Botkin, 1980. A new Paradigm for the Examination of Closed Ecosystems. In. J. P. Giesy, Jr. (ed.), Microcosms in eco- 